\title{
FRACTURE ENERGY OF ILLITIC RAMMED EARTH WITH HIGH WATER-CLAY RATIO
}

\author{
Barbora Mužíková*, Tereza Plaček Otcovská, Pavel Padevět \\ Czech Technical University in Prague, Faculty of Civil Engineering, Department of Mechanics, Thákurova 7, \\ 16629 Prague 6, Czech Republic \\ * corresponding author: barbora.muzikova@fsv.cvut.cz
}

\begin{abstract}
.
The article is focused on design of mixture of rammed earth, producing, testing and determination of fracture energy of unfired rammed earth and its stress-strain curve in tensile bending test. Three different mixtures of rammed earth were designed and tested. The amount of water and binder is one of the key properties of the rammed earth, the amount of the water is expressed by the water-clay ratio. Mechanical properties of the earth material highly depend on the composition of sand, clay and water. The prescription AGL III with $80 \%$ of sand, $20 \%$ of clay and 0.400 water-clay ratio reached the maximum value of fracture energy $4.858 \pm 0.002 \mathrm{~J} / \mathrm{m}^{2}$ and set AGL $\mathrm{V}$ had the minimum value $1.934 \pm 0.310 \mathrm{~J} / \mathrm{m}^{2}$.
\end{abstract}

KEYWORDS: Fracture energy, illite, rammed earth, stress-strain curve, water-clay ratio.

\section{INTRODUCTION}

The rammed earth is nowadays considered as a sustainable way for modern building. The article is focused on illitic rammed earth with high water-clay ratio. The mechanical property that was searched is the fracture energy and stress-strain curve.

Earth as a building material is coming back thanks to the trend to use this natural and traditional material of our ancestors. An expression "sustainable building" describes this trend and unfired earth perfectly meets all its principles. Besides that it is also an environmentally friendly final product which is not synthetically fabricated. Moreover, it is recyclable and there is no need after demolition to take this material to the garbage dump. But the main disadvantage for its using is that the mechanical properties needed for a structure design are not well known. This problem is more complicated because the mechanical properties depend on a composition of the used earth [1-5].

\section{Composition of RAmmed EARTh}

As written before, the mechanical properties depend on the composition of earth. Earth is a mixture of clay, sand and water. From the point of mechanics, the clay is a binder (such as cement for concrete), sand is a filler that makes the structure and water activates the binding forces of clay.

\subsection{BINDER}

The clay is a binder for rammed earth. Unfortunately for searching the mechanical properties, there are three basic types of clay - kaolinite, illite and montmorillonite. They differ in chemical composition. Clay minerals are hydrous aluminium phyllosil- icates with variable amounts of iron, magnesium, alkali metals, alkaline earths. The structure is made by sheets. The number and size of these sheets and gaps between them have an impact on water absorption of the final product.

The clay changes the properties of the final product - mechanical properties and the colour is different as can be seen in the Fig. 3. The specimens tested for the fracture ennergy determination were made with illite clay.

\subsection{FILLER}

The mixture of clay and sand (or sand with bigger parts like gravel) is called a loam. The process of the formation is called an erosion of rocks. It takes a very long time and this process occurs naturally and depends on local weather conditions and surrounding nature. As a result of erosion, the particles of different sizes arise - clay(less than $0.002 \mathrm{~mm})$, silt (0.002 $0.060 \mathrm{~mm})$, sand $(0.060-2.000 \mathrm{~mm})$ and gravel (more than $2.000 \mathrm{~mm}$ ). The smaller parts have the function of a binder and the others have the function of a filler.

\subsection{WATER-CLAY RATIO}

Water is the starter for binding reaction of clay. Thus it is very important to have the suitable amount of water. The amount of water in rammed earth is expressed by the water-clay ratio. The meaning is the same as the water-cement ratio at concrete [6-12].

\section{Production of Specimens}

The principle of building rammed earth using framework is shown in Fig. 1 and the production in laboratory in Fig. 2. First of all, the framework is built to create the shape of the future wall. Secondly, a small part of the earth mixture is put in the framework 


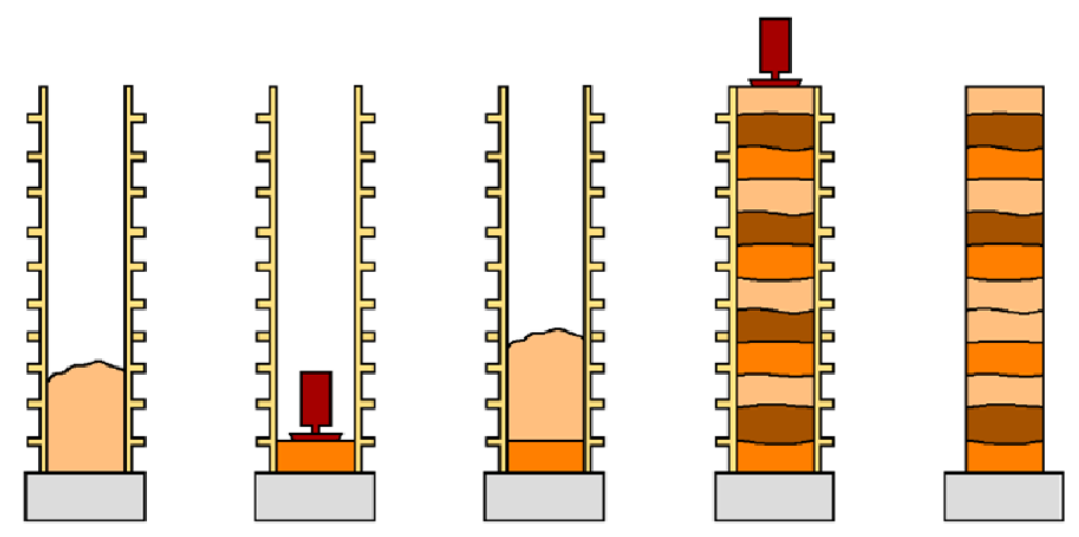

FIGURE 1. Procces of building earth wall.

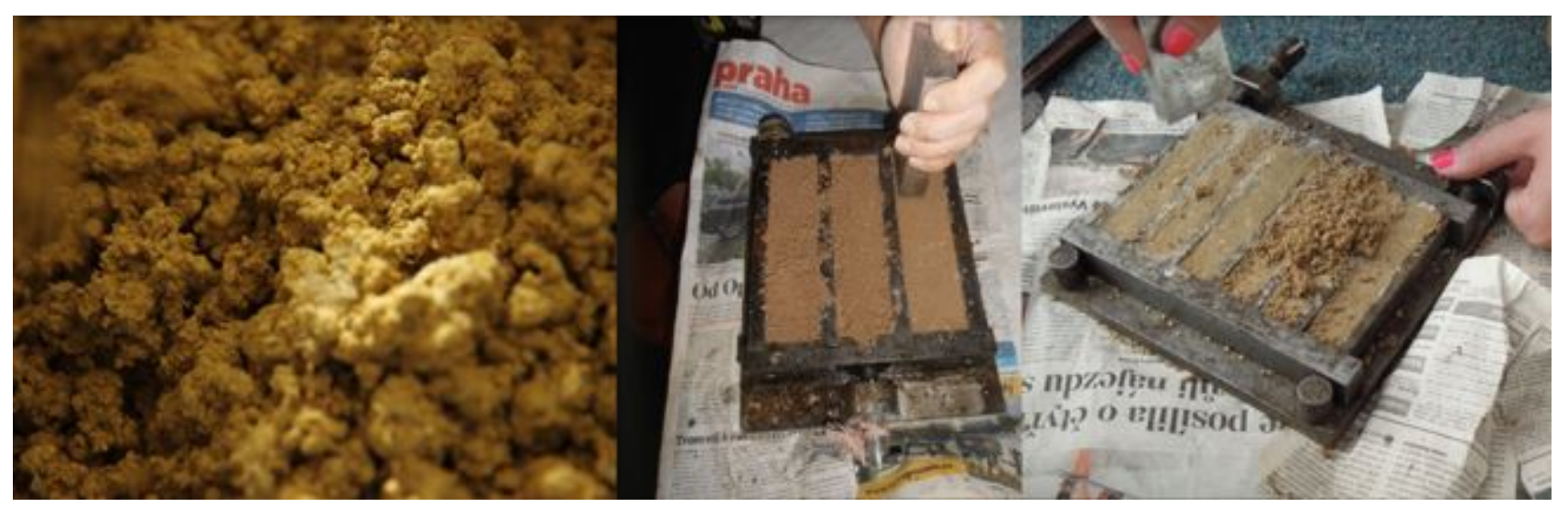

Figure 2. Prefabrication of the specimens in laboratory conditions.

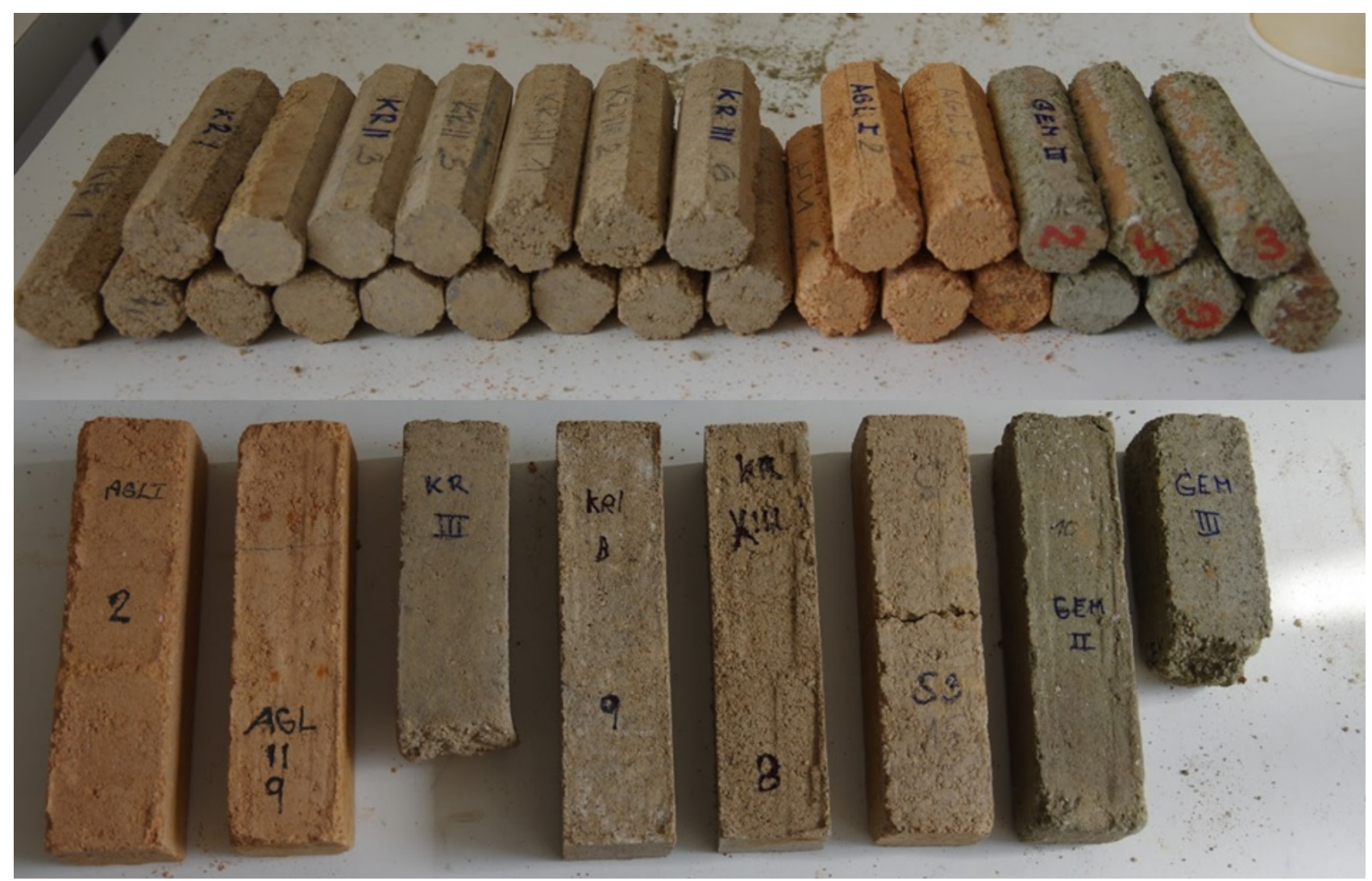

FIGURE 3. Specimens with different type of clay as a binder. 


\begin{tabular}{cccccc}
\hline Set & $\begin{array}{c}\text { Sand/Clay Ratio } \\
{[\% / \%]}\end{array}$ & $\begin{array}{c}\text { Water-Clay Ratio } \\
{[-]}\end{array}$ & $\begin{array}{c}\text { Pcs of specimens } \\
{[-]}\end{array}$ & $\begin{array}{c}\text { Bulk density } \\
{\left[\mathrm{kg} / \mathrm{m}^{3}\right]}\end{array}$ & $\begin{array}{c}\text { Type of clay } \\
{[-]}\end{array}$ \\
\hline AGL III & $80 / 20$ & 0.400 & 3 & 2103 & illite \\
AGL V & $85 / 15$ & 0.370 & 3 & 2005 & illite \\
AGL IX & $80 / 20$ & 0.450 & 3 & 2107 & illite \\
\hline
\end{tabular}

TABLE 1. Composition of designed mixture for rammed earth.

and compressed. Then next layers of rammed earth are put and compressed and together they create the rammed earth wall. As the final step, the framework is removed. In the same way the specimens are made in laboratory, but there is no big framework for the wall but just small ones to create the specimen of exact dimension. The difference is the step before the producing. The prescription has to be chosen. That means to choose a type of clay, then a ratio between clay and filler and a water-clay ratio. The accurate amount of clay, the sand and water are weighed and mixed. For the need of three-point bending test three different prescriptions were designed and tested. The AGL sets III, V and IX are all with illitic clay. The composition of these set is in-depth described in the Table 1.

For the three-point bending test were made specimens of size $40 \times 40 \times 160 \mathrm{~mm}$. Another comperative tests were made in [11-13]. The photograph captured during the test is shown in the Fig. 4.

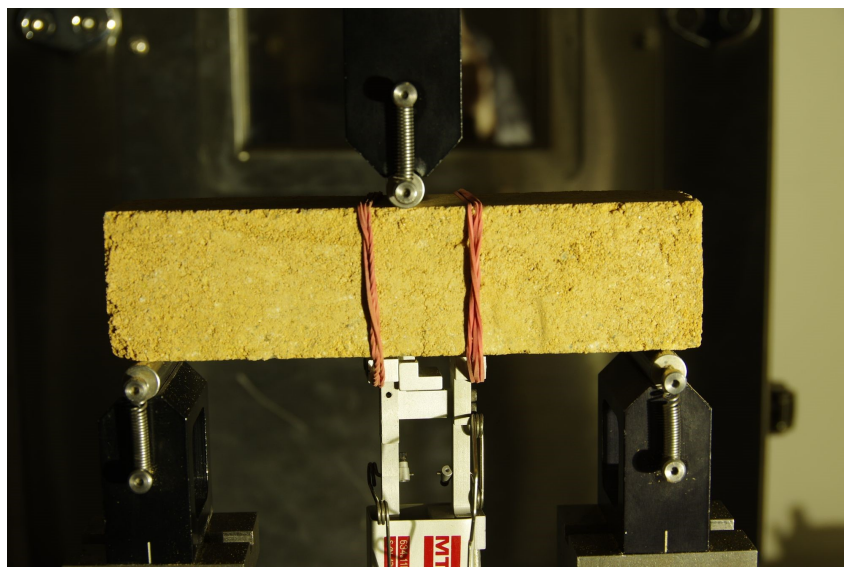

Figure 4. The three-point bending test on specimen from rammed earth material.

\section{Method of Determining FRACTURE ENERGY}

To get fracture energy the three-point bending test needs to be done. The force that is apllied on the specimen and the matching displacement are recorded. The force-displacement curve $(\mathrm{F}-\delta)$ is recorded and the stress-strain curve $(\sigma-\epsilon)$ can be calculated from these data. The get stress-strain we have to caltulate the strain:

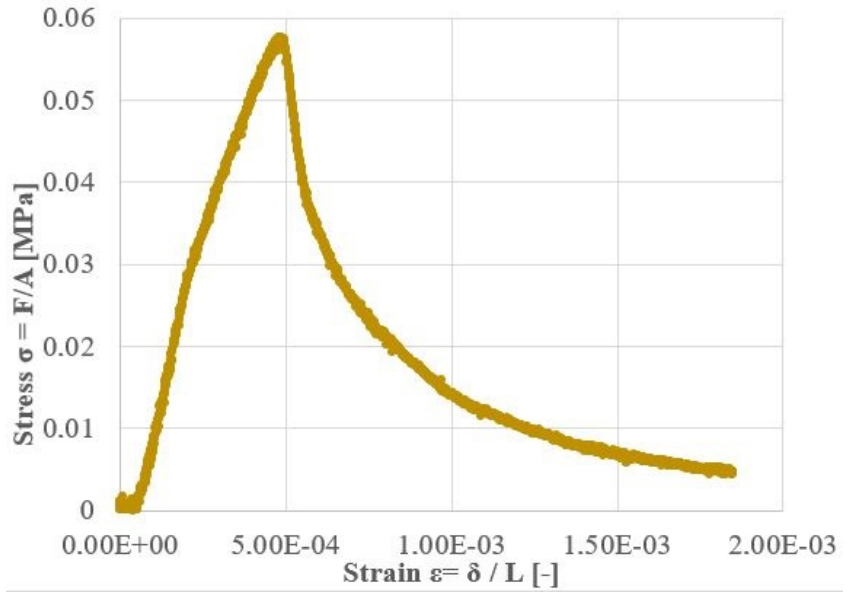

Figure 5. The stress-strain curve for AGL III specimen numb. 3.

$$
\epsilon=\delta \div L
$$

where $L$ is the length of the specimen between the support points in the test. Then the stress can be calculated:

$$
\sigma=F \div A
$$

where $A$ stands for the cross area. Now we have data to get stress-strain curve (Fig. 5). Next step is to calculated the fracture energy. The fracture energy is defined as the amount of energy necessary to create one unit area of a crack. Firstly, the work of the apllied force $W_{f}$ is calculated (7):

$$
W_{f}=\int_{0}^{\delta_{\max }} F \mathrm{~d} \delta,
$$

and then the fracture energy is:

$$
G_{f}=A_{f} \div B W
$$

where $B W$ stands for the area of the crack ( $W$ is the length of the ligament and $B$ is the width of the specimen). In this case this area is the same as the cross area A of the specimen. The schema of the test can be seen in the Fig. 6 . 


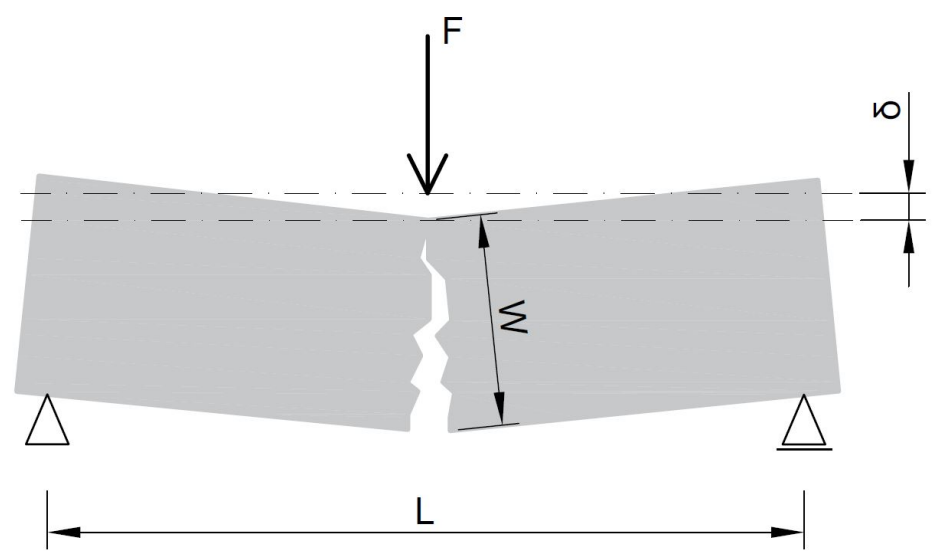

Figure 6. Schema of the three-point bending test.

\begin{tabular}{cccccc}
\hline Set & S/C $-\mathrm{w}$ & $\begin{array}{c}\text { Type of Clay } \\
{[-]}\end{array}$ & $\begin{array}{c}\mathrm{G}_{f} \\
{[-]}\end{array}$ & $\begin{array}{c}\mathrm{f}_{t} \\
{\left[\mathrm{~J} / \mathrm{m}^{2}\right]}\end{array}$ & $\begin{array}{c}\mathrm{E} \\
{[\mathrm{MPa}]}\end{array}$ \\
\hline AGL III & $80 / 20-0.400$ & illite & $4.858 \pm 0.002$ & $0.059 \pm 0.002$ & $68.742 \pm 28.224$ \\
AGL V & $75 / 25-0.370$ & illite & $1.934 \pm 0.310$ & $0.028 \pm 0.003$ & $49.056 \pm 15.171$ \\
AGL IX & $75 / 25-0.450$ & illite & $4.493 \pm 0.521$ & $0.051 \pm 0.001$ & $27.038 \pm 7.597$ \\
\hline
\end{tabular}

TABLE 2. Evaluated fracture energy, tensile strength in bending and modulus of elasticity.

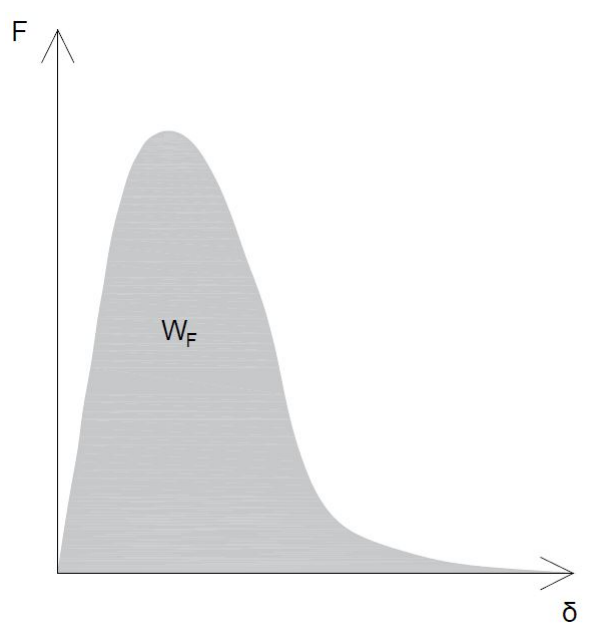

Figure 7. The work to create the crack is the area under $F-\delta$ curve.

\section{Results of the Measurements}

The result of the measurement were the arithmetic mean and the standard deviation for each set from the measured values, they are in Table 2. There are the compositions of the mixture, used type of clay, evaluated fracture energy ( \pm standard deviation), their tensile bending stregths ( \pm standard deviation), elasticity modulus ( \pm standard deviation). The values of fracture energy are shown also in Fig. 8. Set AGL III with water-clay ratio 0.400 has the highest value of the fracture energy $4.858 \pm 0.002 \mathrm{~J} / \mathrm{m}^{2}$, AGL IX with watter-clay ratio 0.450 just a little bit lower value $4.493 \pm 0.521 \mathrm{~J} / \mathrm{m}^{2}$ and set AGL V has significantly

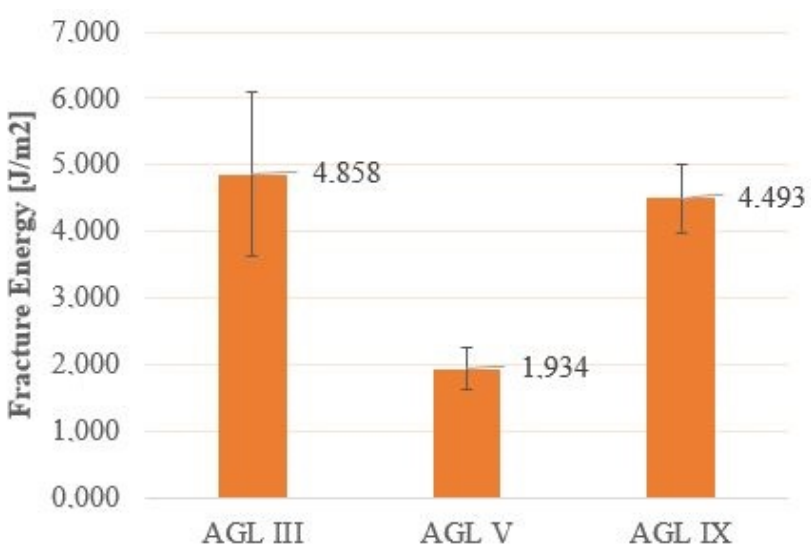

FiguRE 8. Fracture energy of tested mixtures.

lowest value $1.934 \pm 0.310 \mathrm{~J} / \mathrm{m}^{2}$.

It is interesting that set AGL III with $20 \%$ clay and water-clay ratio 0.400 have very simillar result as AGL IX with $25 \%$ clay and water-clay ratio 0.450 . So the set AGL IX have more clay and also more mixing water. Also their tensile strengths are very similar $0.059 \pm 0.002$ and $0.051 \pm 0.001$.

\section{Conclusions}

Three different mixtures were designed, producted and tested. Measured data were evalueted a compared in relation to its composition. The paper was focused on evaluating fracture energy and strainstress curve of different sets of rammed earth. The mechanical properties of the earth material highly depend on the composition of sand, clay and water. 
The amount of water and the binder is one of the key properties of the rammed earth, it is similar to concrete, so the amount of water is expressed by the water-clay ratio. The water-clay ratio 0.400 seems to be optimal with the mixture AGL III (80\% sand and $20 \%$ clay) and also very good results have the composition with water-clay ratio 0.450 for mixture AGL IX (75\% sand and $25 \%$ clay).

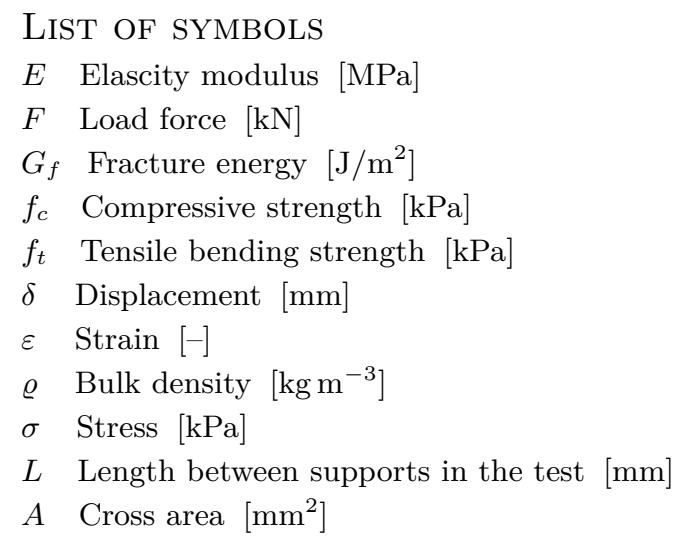

\section{ACKNOWLEDGEMENTS}

This research was financial supported by the Czech Science Foundation (GACR No.18-0884S) and by the Faculty of Civil Engineering at Czech Technical University in Prague (SGS project No.16/201OHK1/3T/11).

\section{REFERENCES}

[1] B. Little, M. Morton. Building with Earth in Scotland: Innovative Design and Sustainability, vol. 1 of First printing. Scottish Executive Central Research Unit, Edinburgh, 2001.

[2] J. Norton. Building with Earth, A Handbook, vol. 1. Intermediate Technology Development Group Limited, London, 1986.

[3] G. Minke. Building with Earth - Design and Technology of Sustainable Architecture, vol. 2. De Gruyter, Berlin, 2009.
[4] I. Zabickova. Hlinené stavby. ERA 21, Brno, 2002.

[5] M. Rauch. Refined earth construction and design with rammed earth, vol. 1. Detail, Munich, 2015.

[6] Kianfar, Ehsan, V. Toufigh. Reliability analysis of rammed earth structures. Construction and Building Materials (127):884-895, 2016.

[7] H. Araki, J. Koseki, T. Sato. Tensile strength of compacted rammed earth materials. Soils and Foundation (56(2)):189-204, 2016.

[8] L. Miccoli, D. V. Oliveira, R. A. Silva, U. Muller. Static behaviour of rammed earth: experimental testing and finite element modelling. Materials and Structures (48(10)):43-56, 2015.

[9] Q. Liu, T. L. Tong. Engineering properties of unstabilized rammed earth with different clay contents. Journal of Wuhan University of Technology: Materials Science (32(4)):914-920, 2017.

[10] R. El-Nabouch, Q. Bui, O. Ple, P. Perrotin. Characterizing the shear parameters of rammed earth material by using a full-scale direct shear box. Construction and Building Materials (171):414-420, 2018.

[11] Q. Bui, J. Morel, B. V. Reddy, W. Ghayad. Durability of rammed earth walls exposed for 20 years to natural weathering. Building and Environment (44(5)):912-119, 2009.

[12] X. Dong, V. Soebarto, M. Griffith. Strategies for reducing heating and cooling loads of uninsulated rammed earth wall houses. Energy and Buildings (77):323-331, 2014.

[13] T. Otcovska, P. Padevet. Dependence of tensile bending strength of rammed earth on used clay composition and amount of mixture water. Modern Methods of Experimental and Computational Investigations in Area of Construction II pp. 48-53, 2017. 